\title{
Sheffield

\section{Experimental Characterization of a Binary Actuated Parallel Manipulator}

CARBONE, Giuseppe <http://orcid.org/0000-0003-0831-8358>

Available from Sheffield Hallam University Research Archive (SHURA) at:

http://shura.shu.ac.uk/11841/

This document is the author deposited version. You are advised to consult the publisher's version if you wish to cite from it.

\section{Published version}

CARBONE, Giuseppe (2016). Experimental Characterization of a Binary Actuated Parallel Manipulator. Chinese Journal Of Mechanical Engineering (Cme), 29 (3).

\section{Copyright and re-use policy}

See http://shura.shu.ac.uk/information.html 


\title{
Experimental Characterization of a Binary Actuated Parallel Manipulator
}

\author{
CARBONE GIUSEPPE*
}

Dept. of Engineering and Mathematics, Sheffield Hallam University, Sheffield, United Kingdom

LARM: Laboratory of Robotics and Mechatronics, University of Cassino and South Latium, Cassino (Fr),Italy

\begin{abstract}
This paper describes the BAPAMAN (Binary Actuated Parallel MANipulator) series of parallel manipulators that has been conceived at LARM. Basic common characteristics of BAPAMAN series are described. In particular, it is outlined the use of a reduced number of active degrees of freedom, the use of design solutions with flexural joints and Shape Memory Alloy (SMA) actuators for achieving miniaturization, cost reduction and easy operation features. Given the peculiarities of BAPAMAN architecture, specific experimental tests have been proposed and carried out with the aim to validate the proposed design and to evaluate the practical operation performance and the characteristics of a built prototype, in particular, in terms of operation and workspace characteristics.
\end{abstract}

Keywords: Parallel Manipulators; Binary actuation, Experimental Characterization.

\section{Introduction}

In the last decades parallel manipulators have been under investigation for their promising features in many fields such as industry, medicine, chemistry or even space applications, as shown, for example, in [1-2]. However, often existing parallel manipulator are complex and expansive. A possible solution for achieving low-cost user-friendly design features for small-size manipulators can be the use of flexural joints, as proposed for example in [3-11]. Often this design solution is used in combination with shape memory alloy actuators (SMA). In fact, SMA provide useful low-cost user-friendly design features, since they are cheap and they can be easily controlled with an on/off logic, [12]. However, a very careful workspace analysis and optimization is required when using flexural joints and SMA. In fact, flexural joints usually can be used within very limited motion ranges also to avoid fatigue failures. Accordingly, flexural joints design must be validated with a very careful FEM analysis for achieving a feasible and durable design solution that can be properly obtained by CNC machining of a single bulk piece of material. Further details and discussion on these aspects can be found for example in [3-7]. Additionally, the use of shape memory alloy actuators (SMA) often limits motion ranges within $4 \%$ of the actuator full length while the resulting workspace is composed of a finite number of reachable poses that have to be carefully identified through binary combinations. Further details on this matter can be found for example in [13-15].

In this paper, specific attention has been addressed to the BAPAMAN (Binary Actuated Parallel MANipulator) series that has been conceived at LARM since 2002, [16]. This is a spatial parallel manipulator that is based on extensive use of flexural joints and SMA actuators. Feasible applications of BAPAMAN architecture can be, for example, as a manipulator

Corresponding author. E-mail: g.carbone@shu.ac.uk, carbone@unicas.it
(C) Chinese Mechanical Engineering Society and Springer-Verlag Berlin Heidelberg 2015

for adjusting the orientation of solar panels, or as a manipulator for modeling human spine discus, or as a module for a multi-module snake-like robot, or as a device for teaching basic robotics and control issues, as outlined in [17-19]. Considering the peculiarities of BAPAMAN manipulators their design can require significant efforts. For example, it is necessary to carefully check the motion range of each flexural joint for validating its operation and the manipulator workspace characteristics.

Experimental activity will be carried out by referring to BAPAMAN version 1 that has been designed and built within a collaboration between LARM laboratory and TU Braunschweig in Germany as also detailed in [17-19]. In particular, the BAPAMAN1 prototype will be tested by developing two specific experimental set-ups. A first experimental set-up is based on the Milli-CaTraSys (Milli-Cassino Tracking System) testing device that has been developed at LARM as reported for example in [20-21]. This experimental set-up is used to verify the workspace and motion ranges of BAPAMAN1 when a known load is applied on its movable plate. A second set of experiments has been made by using a non-contact motion analysis equipment, whose name is CONTEMPLAS, [22]. This experimental set-up has been used to verify the motion ranges of each joint and workspace characteristics of BAPAMAN1 when no external load is acting on it. Results of the proposed experimental tests are used for validating BAPAMAN1 design and operation as well as for identifying possible design improvements.

\section{Novel Parallel Manipulator}

The BAPAMAN design is based on a parallel architecture, which is composed of a fixed plate FP and a 
moving plate MP that are connected by 3 legs. Each leg is made of a single piece of plastic where proper notches have been CNC milled to achieve 3 flexural joints, two 1 DOF revolute joints $\mathrm{Ri}$ and one $2 \mathrm{DOF}$ joint $\mathrm{Ui}$, as shown in the schemes in Fig.1. The 2 DOF Ui joints has been fixed on MP and practically consists of two 1 DOF flexural joints. Thus, each leg mechanism can be considered as an URR kinematic chain. Globally, each module has 5 degrees of mobility (3 translations, pitch and yaw). Each module can reach 23 discrete configurations, since it has 3 legs and each leg has two antagonistic binary actuators, which can change their configuration only into 2 binary states. Accordingly, BAPAMAN has 8 operation modes, which are named as OP0-OP7 as listed in Table 1 . The number 1 in Table 1 means that a leg is activated while the number 0 means that a leg is deactivated. In particular, OP0 is a stationary mode, in which all the legs are deactivated. In OP1, OP2, and OP4 modes only one leg is activated. In OP3, OP5, and OP6 modes two legs are activated. In OP7 mode, all legs are activated.

As illustrated in the kinematic scheme of Fig. 1b), design parameters of the $\mathrm{k}$-th leg mechanism $(\mathrm{k}=1 \ldots 3)$ can be identified through the link lengths ak and bk. The kinematic variables are the input joint angles $\alpha \mathrm{i},(\mathrm{i}=1,2,3)$, which are determined by the output displacements of the SMA actuators. $\mathrm{Hk}$ is the articulation point at which the $\mathrm{k}$-th leg mechanism is fixed on the MP. The MP is driven by the three leg mechanisms through the corresponding articulation points $\mathrm{H}_{1}, \mathrm{H}_{2}$, and $\mathrm{H}_{3}$. Polyoxymethylen plastic material has been selected for the construction of BAPAMAN1, since it is cheap, lightweight, flexible, and it can be easily manufactured. The main dimensions of the above kinematic parameters for BAPAMAN1 are listed in Table 2. Each actuated joint has a feasible operation range from $-10 \mathrm{deg}$ to $+35 \mathrm{deg}$.

The binary behavior is a fundamental characteristic of BAPAMAN architecture that limits the number of its feasible configurations. Nevertheless, a quasi-continuous mobility can be achieved by assembling several BAPAMAN modules in a serial chain architecture as in Fig.2. For example, a snake-like robotic arm consisting of 5 modules will have $2^{(3 \times 5)}$ discrete configurations. Thus, a large number of modules can approximate a continuous extremity motion.

Key characteristics and critical issues for BAPAMAN design can be identified as referring to the flexural joints and the SMA actuation. In fact, the lightweight non-metallic material for the flexural joints seems promising but can limit the stiffness of the whole architecture. Moreover, even very small design changes may affect the kinematic behavior as well as the feasible motion ranges. Additionally, the thickness of notches should be carefully designed, since, for example, thin notches are

Table 1 - Operation modes for the BAPAMAN1

\begin{tabular}{|c|c|c|c|c|c|c|c|c||}
\hline $\begin{array}{c}\text { Operation } \\
\text { mode }\end{array}$ & OP0 & OP1 & OP2 & OP3 & OP4 & OP5 & OP6 & OP7 \\
\hline Leg 1 & 0 & 0 & 0 & 0 & 1 & 1 & 1 & 1 \\
\hline Leg 2 & 0 & 0 & 1 & 1 & 0 & 0 & 1 & 1 \\
\hline Leg 3 & 0 & 1 & 0 & 1 & 0 & 1 & 0 & 1 \\
\hline
\end{tabular}

useful to improve power consumption and kinematic behavior but at same time they may more easily produce fatigue failures.
Table 2 - Geometry dimensions of the BAPAMAN1

\begin{tabular}{|c|c|c|c|c|c||}
\hline $\begin{array}{c}\mathrm{a}_{\mathrm{k}} \\
(\mathrm{mm})\end{array}$ & $\begin{array}{c}\mathrm{b}_{\mathrm{k}} \\
(\mathrm{mm})\end{array}$ & $\begin{array}{c}\mathrm{r}_{\mathrm{f}} \\
(\mathrm{mm})\end{array}$ & $\begin{array}{c}\mathrm{r}_{\mathrm{p}} \\
(\mathrm{mm})\end{array}$ & $\begin{array}{c}\delta_{\mathrm{k}} \\
(\mathrm{deg})\end{array}$ & $\begin{array}{c}\gamma_{\mathrm{k}} \\
(\mathrm{deg})\end{array}$ \\
\hline 100.0 & 100.0 & 90.0 & 90.0 & 120.0 & 120.0 \\
\hline
\end{tabular}
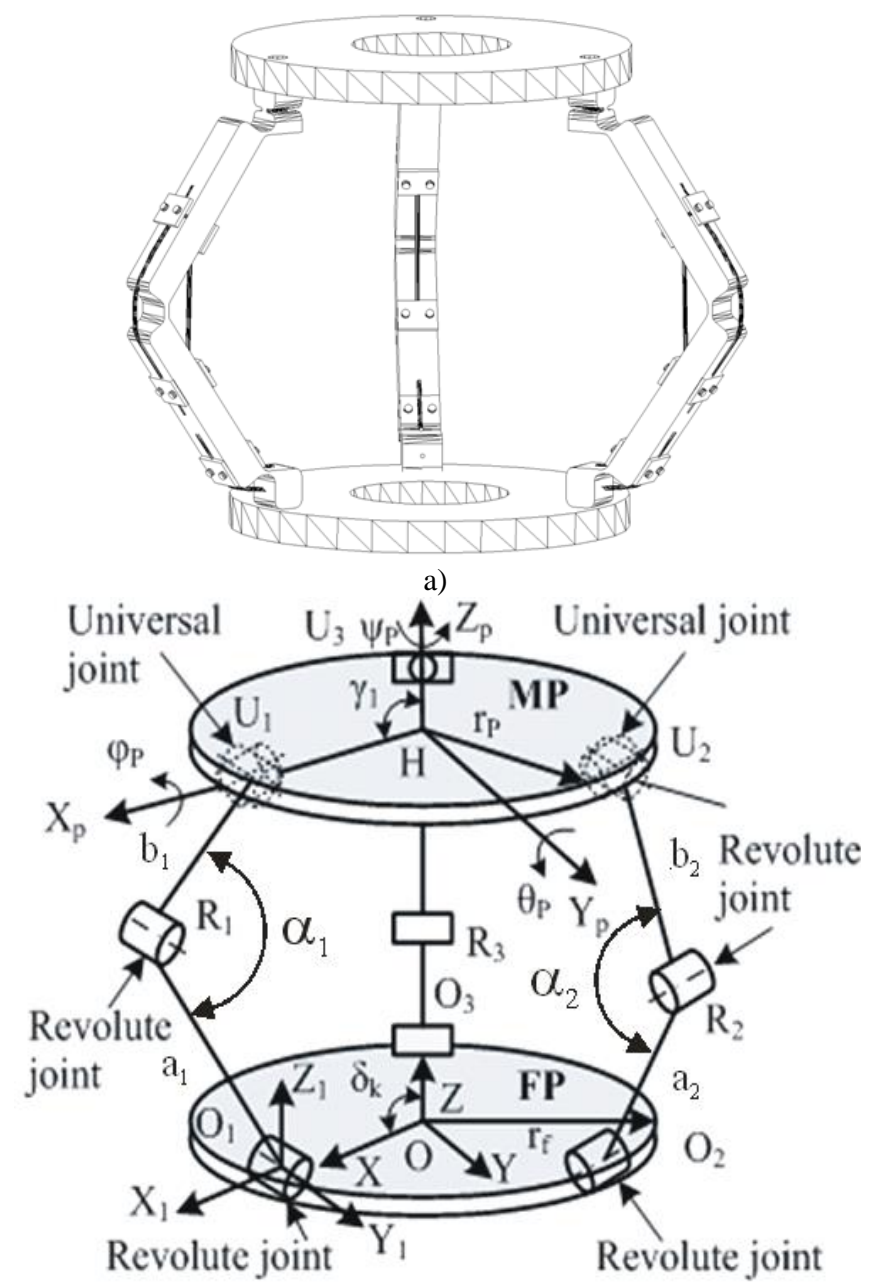

b)

Fig. 1 Details of BAPAMAN (Binary Parallel Manipulator): a) a CAD model with location of SMA wires actuation; b) a detailed kinematic scheme.

Accordingly, very careful FEM analyses have to be carried

out for achieving a feasible design solution. The proposed design solution must also comply with the CNC machining constraints for being obtained from a single piece of plastic.

The SMA actuators are usually made by using NiTiNol wires, [12]. However, several aspects need to be considered at design stage. For example, length, shape and thickness characteristics of a SMA wire will affect the motion ranges and the actuator force output as well as the operation time. In fact, a SMA actuator needs to cool down before being actuated again. This problem can be significantly reduced by using antagonistic SMA wires for each actuated joint, as proposed in Fig.1a).

Nevertheless, SMA has the need of continue powering even if the device is stationary. Additionally, if an actuator lets a joint move out of its design operation range this may lead to fatigue failures even after few operation cycles. Several other aspects and constraints have been considered for a proper design 
solution. Among others it has been attempted to have a large motion range of the movable plate along Z-direction with a relatively large rotation of the actuated joints up to 35 degrees.

A built prototype of BAPAMAN1 is shown in Fig.3a).Error! Reference source not found. For easy assembling and testing, BAPAMAN1 has been fixed on a a support frame with MP upward and FP downward. Actuators of BAPAMAN 1 consist of NiTiNol SMA wires with a diameter of $0.2 \mathrm{~mm}$ that have been twisted in a multi coil shape in order to increase their length and motion ranges. As shown in Fig. 3b), BAPAMAN 1 has been equipped with antagonistic actuators for each leg (one internal and one external). Other joints are passive.
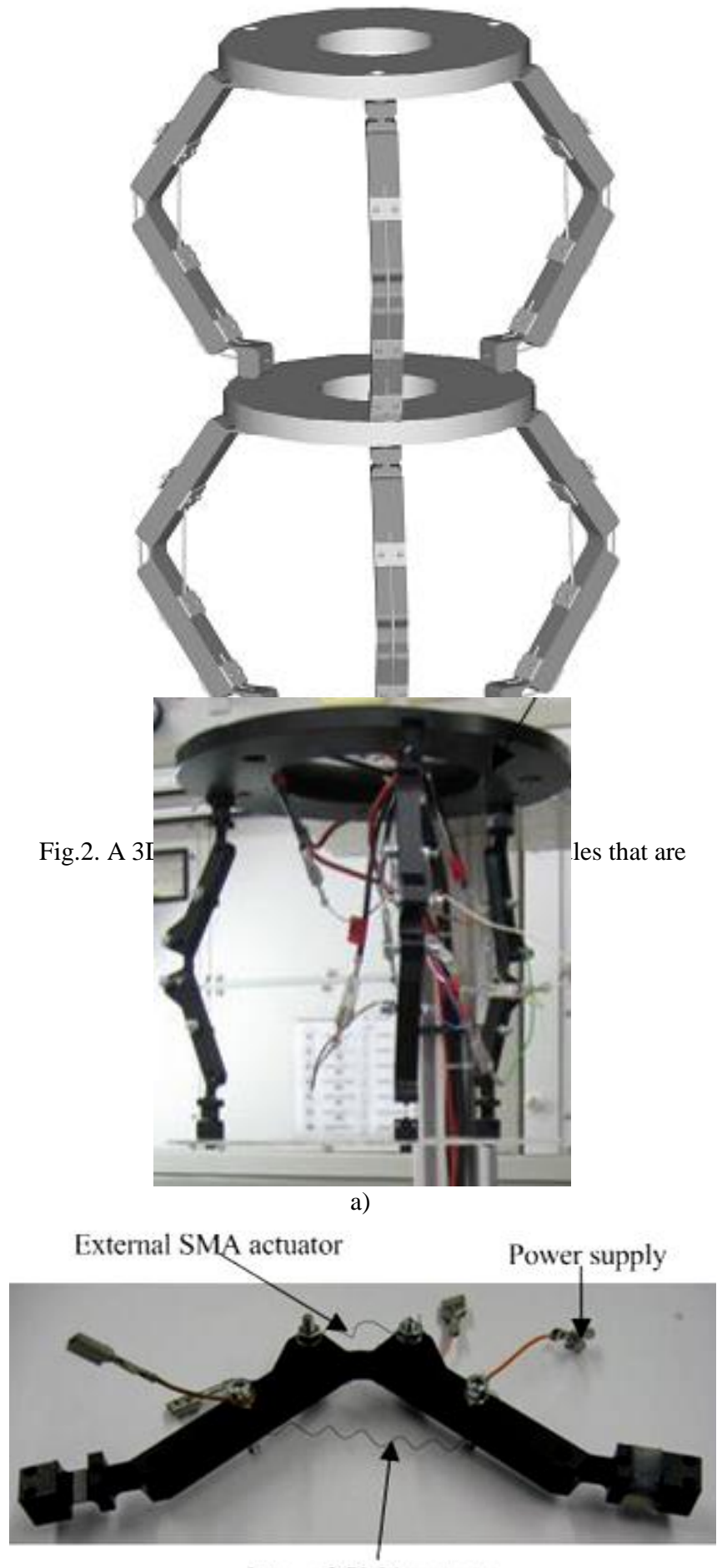

Internal SMA actuator

b)

Fig. 3. BAPAMAN1 : a) a built prototype; (b) a detail of one leg.

\section{Experimental Tests with Milli-CaTraSys}

A suitable measuring system has been used to measure the position of the end-effector of BAPAMAN1. The proposed measuring system, whose name is Milli-CaTraSys (Cassino Tracking System) has been developed at LARM as reported for example in $[19,20]$. It is a cable-based design which is based on a parallel manipulator configuration with 3-2-1 Gough-Stewart architecture. The kinematics of this type of measuring system has been solved in a closed form as a result of its special architecture by applying the trilateration technique. Moreover, Milli-CaTraSys can be used to apply a known set of forces on the end-effector of a robotic system and, simultaneously, to measure the corresponding end-effector displacements. In fact, Milli-CaTrasys can apply known masses mi (with $i=1, \ldots, 6$ ) on the free ends of its cables. This feature is very useful to verify the relations between the forces that are applied to the movable plate and the consequent displacements as successfully reported even for stiffness estimation in [23].

A setup of the Milli-CaTraSys tracking system for measuring the motion of BAPAMAN1 is shown in Fig. 4. Milli-CaTraSys consists of a fixed platform and a specific design end-effector with six cables. A set of six LVDT transducers is fixed at the end of each cable to determine the length change. The data acquisition and elaboration are executed by a NI DAQ data acquisition PCI 6024 card and a virtual instrument program in LABVIEW environment. The six cables of Milli-CaTrasys are fixed on BAPAMAN1 through the three points $\mathrm{H}_{1}, \mathrm{H}_{2}$, and $\mathrm{H}_{3}$ on attachment of the universal joints to the MP.

In particular, three cables have been attached to point $\mathrm{H}_{1}$, two have been attached to point $\mathrm{H}_{2}$, and one has been attached to point $\mathrm{H}_{3}$. These points on the MP define an equivalent triangle. The motion control of BAPAMAN1 is implemented by switches that are manually operated. A program has been developed in the LabVIEW environment to handle the acquired data.

By measuring the length of the cables and using a trilateration technique, the position and orientation of the Milli-CaTraSys end-effector can be determined in Cartesian space. This technique is based on suitable algebraic manipulations of distances li as function of the Cartesian coordinates $\mathrm{xHi}, \mathrm{yHi}$, and $\mathrm{zHi}$ of an attaching points $\mathrm{Hi}$ on the movable plate MP with respect to the fixed frame O-XYZ. For example, for the point $\mathrm{H} 1$ one can write

$\mathrm{l}_{\mathrm{i}}^{2}=\left(\mathrm{x}_{\mathrm{H} 1}-\mathrm{x}_{\mathrm{Bi}}\right)^{2}+\left(\mathrm{y}_{\mathrm{H} 1}-\mathrm{y}_{\mathrm{Bi}}\right)^{2}+\left(\mathrm{z}_{\mathrm{H} 1}-\mathrm{z}_{\mathrm{Bi}}\right)^{2},(\mathrm{i}=1,3,5)$

where $\mathrm{x}_{\mathrm{Bi}}, \mathrm{y}_{\mathrm{Bi}}$, and $\mathrm{z}_{\mathrm{Bi}}$ are the Cartesian coordinates of the known fixed points $\mathrm{Bi}$ at the Milli-CaTraSys support frame. After some algebraic manipulation, the position of $\mathrm{H} 1$ can be computed through its components as 


$$
\begin{aligned}
& \mathrm{x}_{\mathrm{H} 1}=\mathrm{H}_{\mathrm{x}}\left(-\mathrm{B}_{2}-\sqrt{\mathrm{B}_{2}^{2}-4 \mathrm{~B}_{1} \mathrm{~B}_{3}}\right) / 2 \mathrm{~B}_{1}+\mathrm{E}_{\mathrm{x}} \\
& \mathrm{y}_{\mathrm{H} 1}=\mathrm{H}_{\mathrm{y}}\left(-\mathrm{B}_{2}-\sqrt{\mathrm{B}_{2}^{2}-4 \mathrm{~B}_{1} \mathrm{~B}_{3}}\right) / 2 \mathrm{~B}_{1}+\mathrm{E}_{\mathrm{y}} \\
& \mathrm{z}_{\mathrm{H} 1}=\left(-\mathrm{B}_{2}-\sqrt{\mathrm{B}_{2}^{2}-4 \mathrm{~B}_{1} \mathrm{~B}_{3}}\right) / 2 \mathrm{~B}_{1}
\end{aligned}
$$

where

$$
\begin{aligned}
& \mathrm{B}_{1}=\mathrm{H}_{\mathrm{x}}^{2}+\mathrm{H}_{\mathrm{y}}^{2}+1 \\
& \mathrm{~B}_{2}=2 \mathrm{H}_{\mathrm{x}}\left(\mathrm{E}_{\mathrm{x}}-\mathrm{x}_{3}\right)+2 \mathrm{H}_{\mathrm{y}}\left(\mathrm{E}_{\mathrm{y}}-\mathrm{y}_{3}\right)-2 \mathrm{z}_{3} \\
& \left.\mathrm{~B}_{3}=\mathrm{E}_{\mathrm{x}}^{2}+\mathrm{E}_{\mathrm{y}}^{2}+\mathrm{A}_{3}^{2}-2 \mathrm{E}_{\mathrm{x}} \mathrm{x}_{3}-2 \mathrm{E}_{\mathrm{y}} \mathrm{y}_{3} \mathrm{~B}_{1}\right) \\
& \mathrm{H}_{\mathrm{x}}=-\left(\mathrm{Z}_{21}+\mathrm{H}_{\mathrm{y}} \mathrm{Y}_{21}\right) / \mathrm{X}_{21} \\
& \mathrm{E}_{\mathrm{x}}=\left(\mathrm{A}_{1}+\mathrm{A}_{2}-\mathrm{E}_{\mathrm{y}} \mathrm{Y}_{21}\right) / \mathrm{X}_{21} \\
& \mathrm{E}_{\mathrm{y}}=\left(-\mathrm{A}_{1}+\mathrm{A}_{2}\right) / \mathrm{Y}_{32} \mathrm{X}_{21}
\end{aligned}
$$

where

$$
\begin{aligned}
& A_{j}=l_{i}^{2}-x_{i}^{2}-y_{i}^{2}-z_{i}^{2} \\
& X_{i j}=x_{i}-x_{j} \\
& Y_{i j}=y_{i}-y_{j} \\
& Z_{i j}=z_{i}-z_{j}
\end{aligned}
$$

with $(\mathrm{i}, \mathrm{j}=1,2,3),(\mathrm{i} \neq \mathrm{j})$, and (xi yi zi) are the Cartesian coordinates of the points Hi.

It is to note that one of the key issues in using Milli-CaTraSys system is to set-up a proper arrangement of cables so that they do not have interferences/contacts among them and/or with the device under testing during the whole motion tests. Given the small distances among the cables this results in a need to carefully verify and eventually limit the motion ranges of each cable to very small values. The cable arrangements and configurations have to be carefully considered also because they can significantly affect the Milli-CaTraSys accuracy. This issue has been investigated in refs. [20-21] where different cable arrangements and configurations have been considered. Based on these previous experiences an average accuracy of $0.1 \mathrm{~mm}$ can be expected for the Milli-CaTraSys set-up that has been used in this paper.

\section{Experimental Results with Milli-CaTraSys}

A specific operation planning has been defined to let BAPAMAN 1 move through its whole feasible workspace. In particular, BAPAMAN 1 can achieve 8 operation modes (OP0 to OP7) as defined in Table 1. Each operation mode corresponds to one feasible configuration of BAPAMAN 1. Thus, experimental tests have been carried out by switching sequentially among the 8 operation modes, namely, from OP0 to OP7. Figure 5 shows the 8 configurations that have been reached by BAPAMAN 1 during the above-mentioned experimental tests.

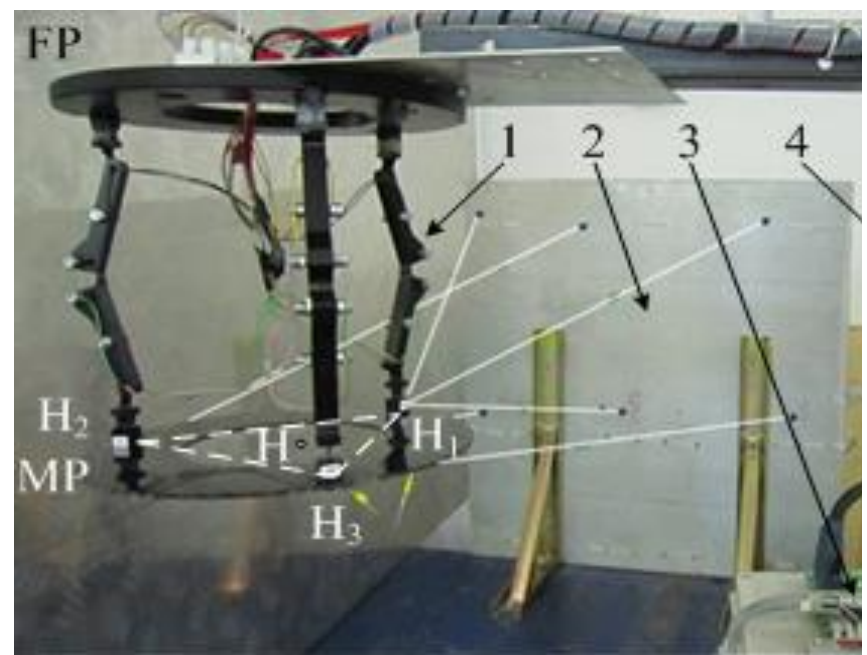

Fig.4. The experimental set up with Milli-Catrasys (1-CAPAMAN1; 2-Milli-CaTraSys; 3-data acquisition device; 4-On/Off switches.

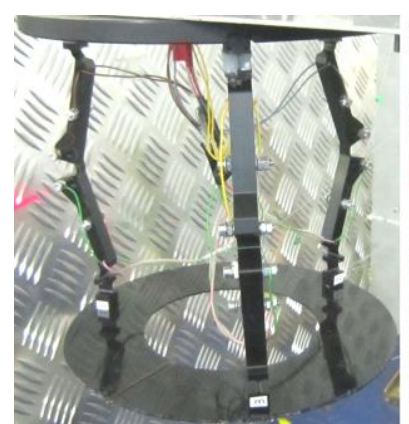

a)

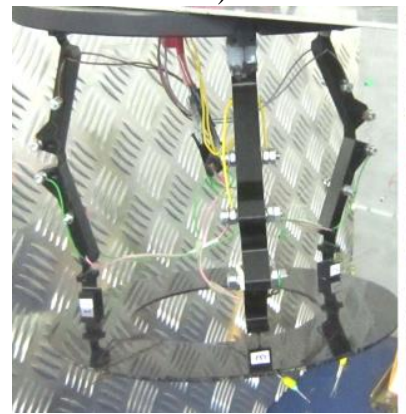

c)

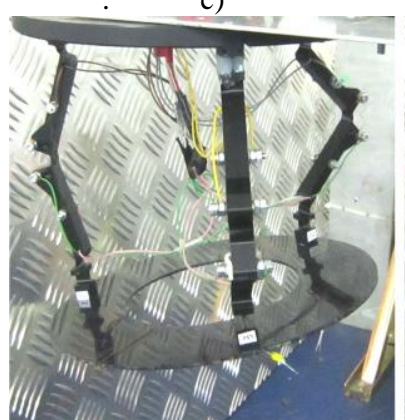

e)

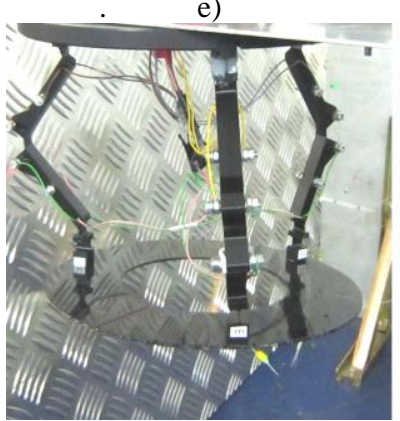

g)

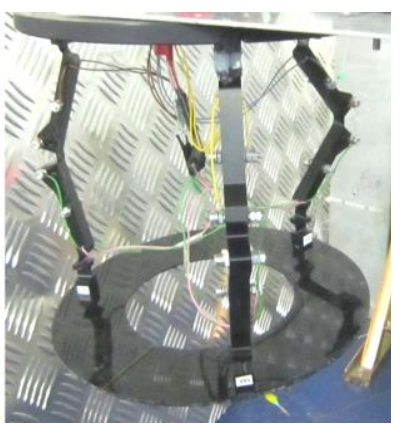

b)
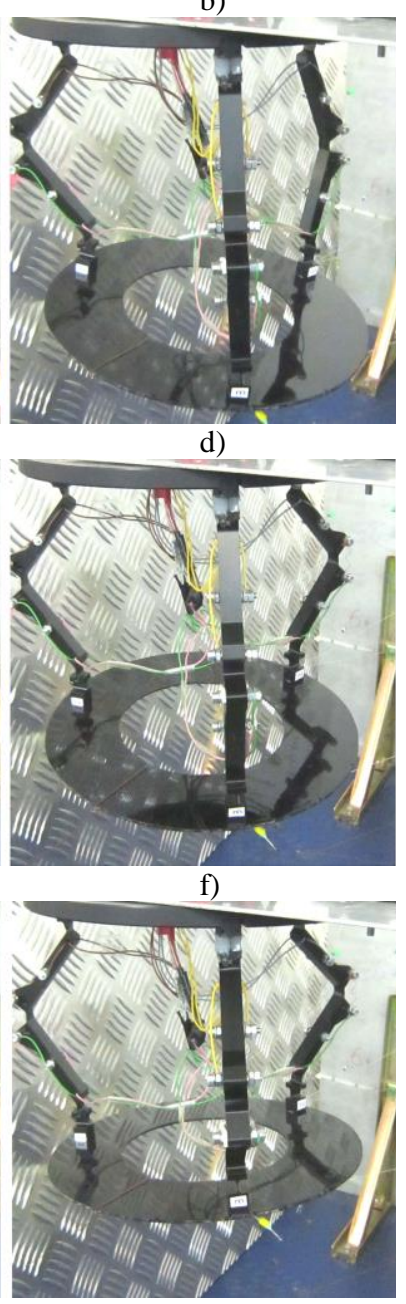

h)
Fig. 5. Snapshots of eight binary configurations of the tested prototype of BAPAMAN1: a) OP0; b) OP1; c) OP2; d) OP3; e) OP4; f) OP5; g) OP6; h) OP7. 
During the experimental tests the Milli-CaTraSys measurement system provides the measured values of the length of each cable that has been connected to the BAPAMAN 1 prototype. For example, Fig. 6 shows the plots of the lengths of the cables as function of time that have been obtained by means of Milli-CaTraSys during a sequential switching among the 8 operation modes that are shown in Fig.5. The proposed experimental test in Fig.6 has a total duration of 200 seconds. The change of operation mode is made manually approximately each 25 seconds. Coordinates of point $\mathrm{H}$ have been computed by using the measured lengths of the cables that have been obtained by means of Milli-CaTraSys. Thus, by using the data in the plots of Fig. 6 it has been possible to obtain plots of the motion ranges of point $\mathrm{H}$ such as reported in Figs. 7 and 8. The plots of Figs.7 and 8 refer to the measured lengths of cables that have been shown in the plots of Fig.6. In particular, Fig.7a) to Fig.7(c) show x-, y-, and $\mathrm{z}$ - coordinates as function of time, respectively. Similarly, Fig.8 shows the 3D trajectory of point H. Several experimental tests have been carried to validate the workspace of
BAPAMAN 1 In particular, maximum motion ranges have been found to be $2.3 \mathrm{~mm}, 0.1 \mathrm{~mm}, 3.2 \mathrm{~mm}$ in $\mathrm{X}-$, $\mathrm{Y}-$, Zdirections, respectively. These values are significantly lower than the expected maximum motion ranges for BAPAMAN 1 that have been set up at the early design stage. In fact, the SMA actuators of BAPAMAN 1 have been designed to provide a maximum value of the angles $\alpha 1, \alpha 2, \alpha 3$ (Fig.1b) as equal to 35 degs. This value should correspond to a maximum displacement along Z- direction as about $43 \mathrm{~mm}$. On this matter one should note that the tension of cables of Milli-CaTraSys is usually in about $0.5 \mathrm{~N}$. Even if the applied tension of cables is relatively small, non negligible compliant displacements are obtained on BAPAMAN 1 prototype. Accordingly, a second testing round has been made by means of the non-contact CONTEMPLAS measuring system. Differences between the results obtained with the two measuring systems (Milli-CaTraSys and CONTEMPLAS) will give also an estimation of the compliance characteristics of BAPAMAN prototype.

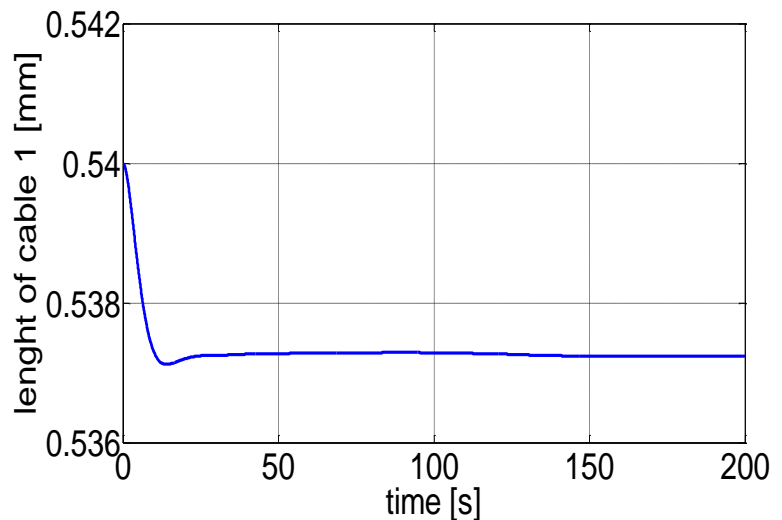

(a)

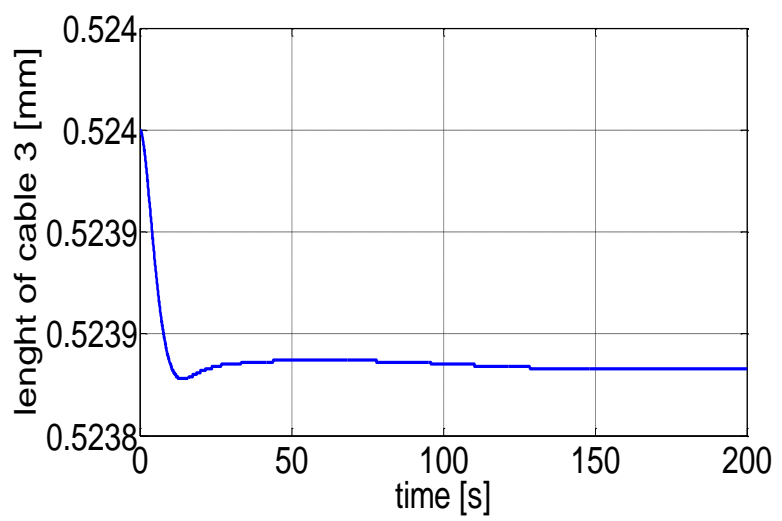

(c)

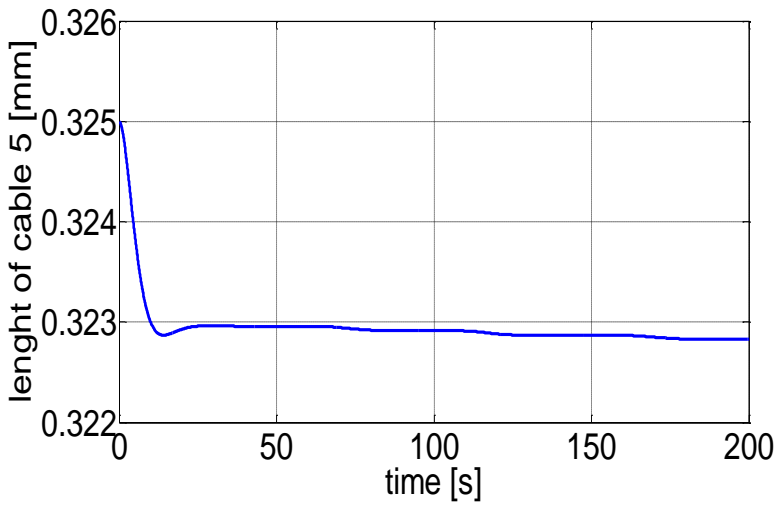

(e)

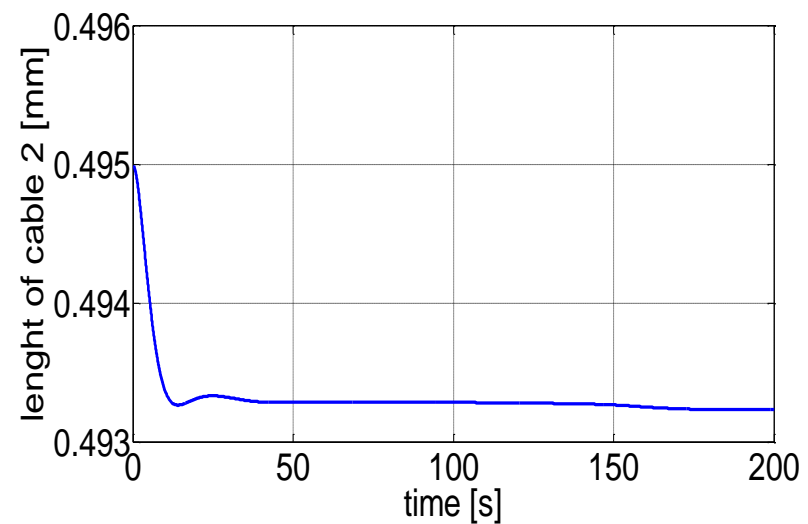

(b)

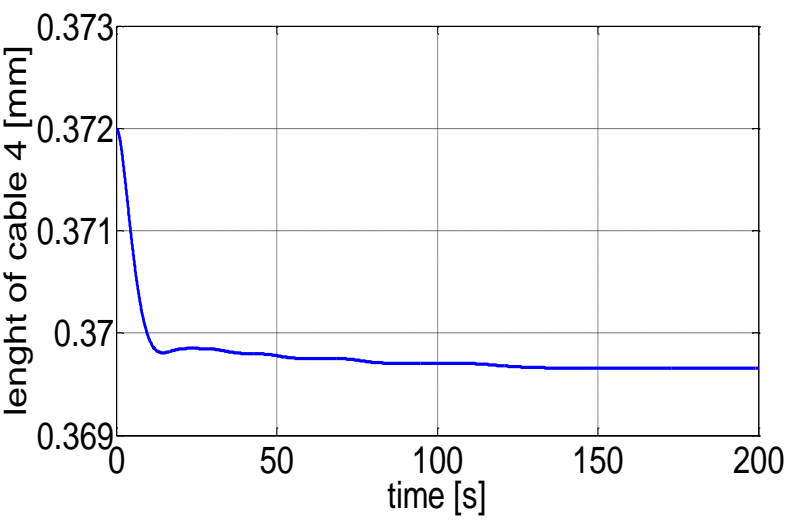

(d)

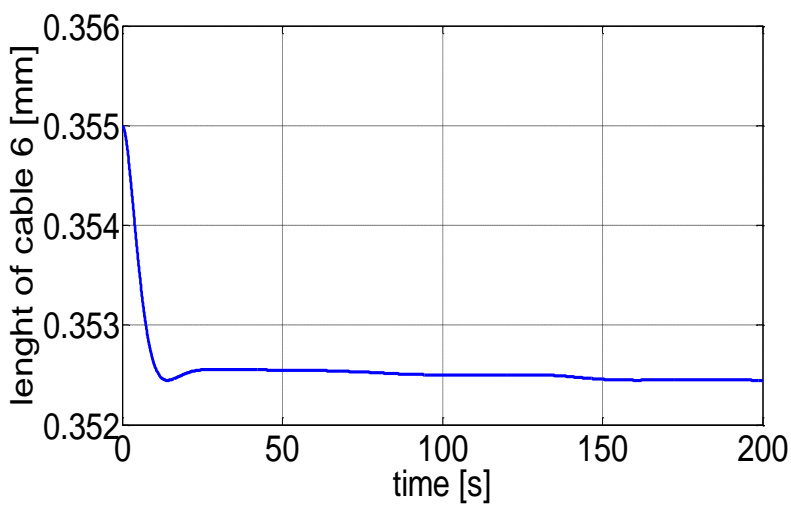

(f)

Fig. 6. Plots of the lengths of the cables versus time as measured by MiliiCaTraSys during a sequential switching of the operation models of BAPAMAN 1 from OP1 to OP7 (Fig.7): (a) cable 1: (b) cable 2: (c) cable 3: (d) cable 4: (e) cable 5: (f) cable 6. 


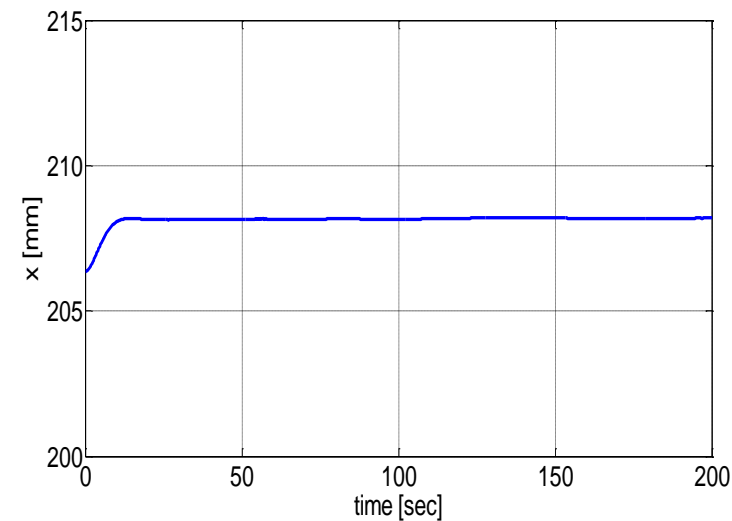

a)

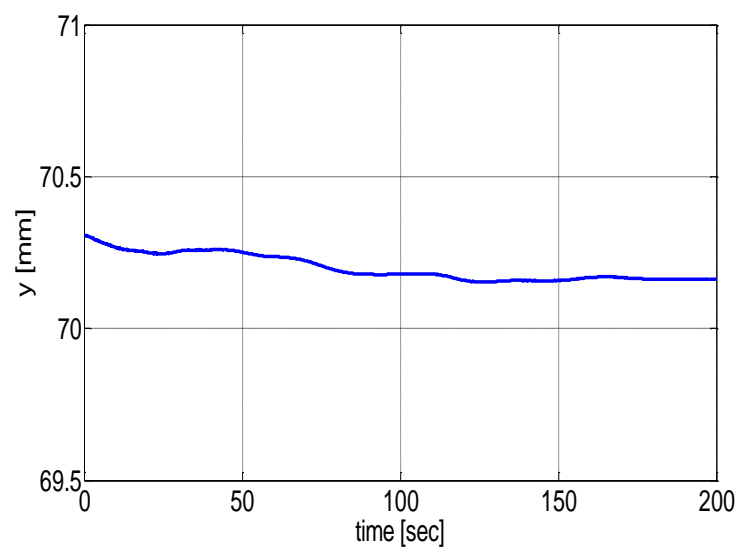

b)

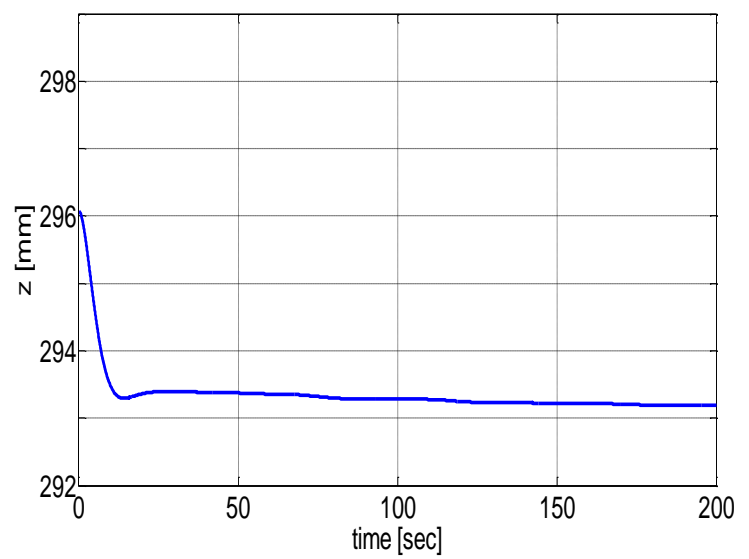

(c)

Fig. 7. Computed positions of the centre point $\mathrm{H}$ of BAPAMAN 1 by using the measured data in Fig.6: a) $\mathrm{x}_{\mathrm{H}}$; b) $\mathrm{y}_{\mathrm{H}}$; c) $\mathrm{z}_{\mathrm{H}}$.

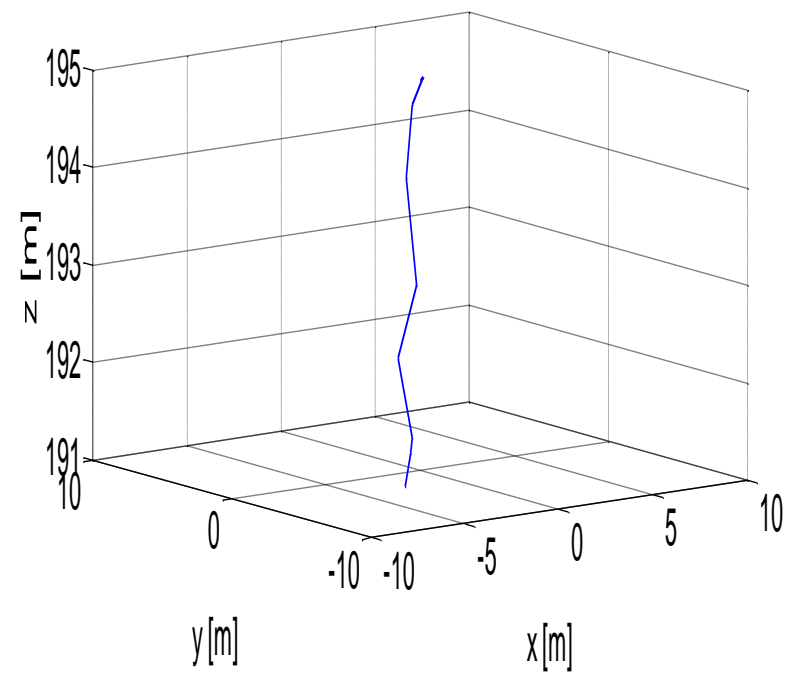

Fig. 8. A 3D trajectory of the center point $\mathrm{H}$ of BAPAMAN 1 that has been computed by using the measured data in Fig. 6.

\section{Experimental Tests with CONTEMPLAS}

A specific set-up has been developed in order to determine the BAPAMAN 1 operation when no external load is acting on it. This set up is based on a CONTEMPLAS system [22] that has been properly located close to BAPAMAN 1 manipulator. The equipment configuration is composed of 2 high speed cameras, two tripod frames, a Gigabit Ethernet ExpressCard, a dedicated laptop computer as shown in Fig.9. Special markers with reflexive properties are attached to the points under investigation on BAPAMAN 1 prototype. In particular, markers are attached to joint centres for tracking and measuring their specific motion properties.

The proposed set-up is capable to generate automatically the plots of trajectories and joint angles of BAPAMAN 1 in real time. It is also possible to record and store motion data for a more careful post-processing analysis. The markers that have been attached on BAPAMAN 1 manipulator are shown in Fig.10. The desired measured trajectories are the ones that are generated by markers M7, M8 and M9 on the upper side of the movable plate MP, and M7', M8' and M9' on the lower side of the movable plate MP in correspondence of the centres of the universal joints, as shown in Fig.10 a) and b). Also the joint angle motion range of each leg $(\alpha 1, \alpha 2$ and $\alpha 3)$ is acquired during experimental tests.

A calibration procedure has been carried out for identifying the correspondence between the equipment global reference system and the local reference frame that is attached on the BAPAMAN1 upper platform (XYZ). The calibration procedure has been set up by taking into account the distance between the prototype and the high-speed video cameras. The used CONPTEMPLAS equipment includes a dedicated software, which allows a user to analyze the obtained motion results, [22]. The setup time for the experimental tests has been about one hour. This time has been sufficient to place markers on the desired joints and links; to properly locate the high speed cameras so that they can properly view all the markers during the tests; to set up the equipment according to the ambient luminosity and desired frame rate for video recording; to measure the relative position of the cameras with respect to the BAPAMAN 1 for the initial calibration.

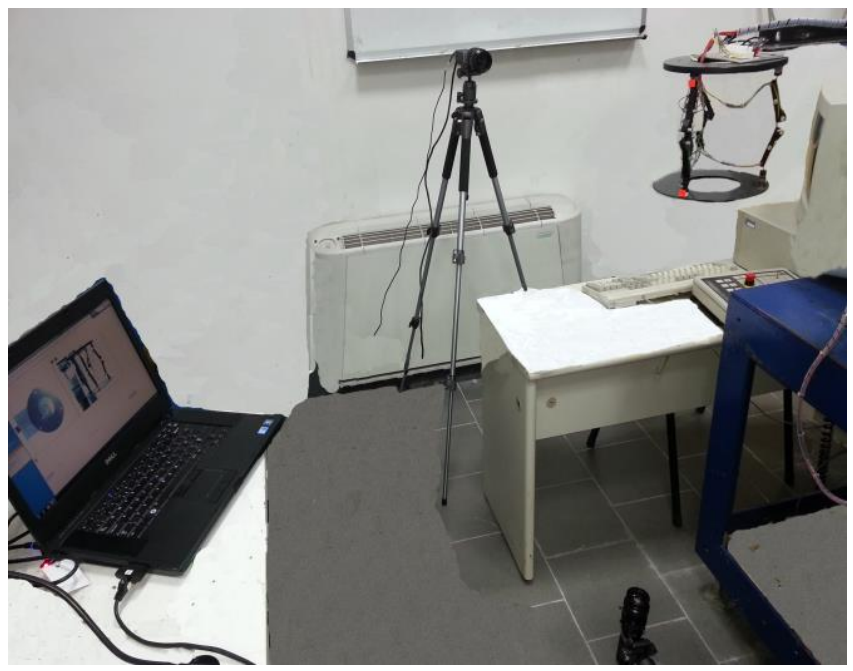

Fig. 9. Experimental set up for BAPAMAN1 with the CONTEMPLAS system. 


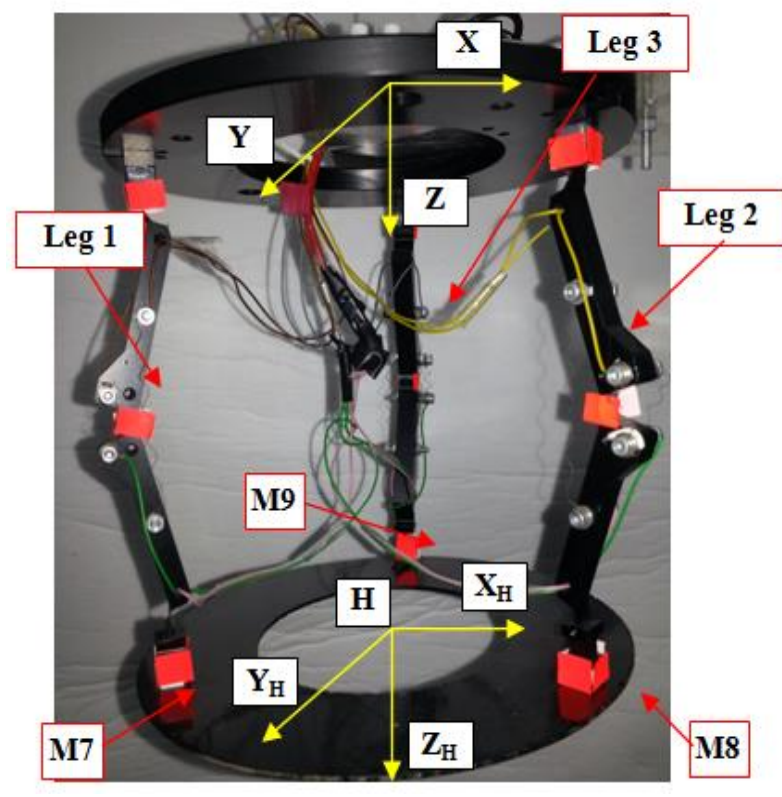

a)

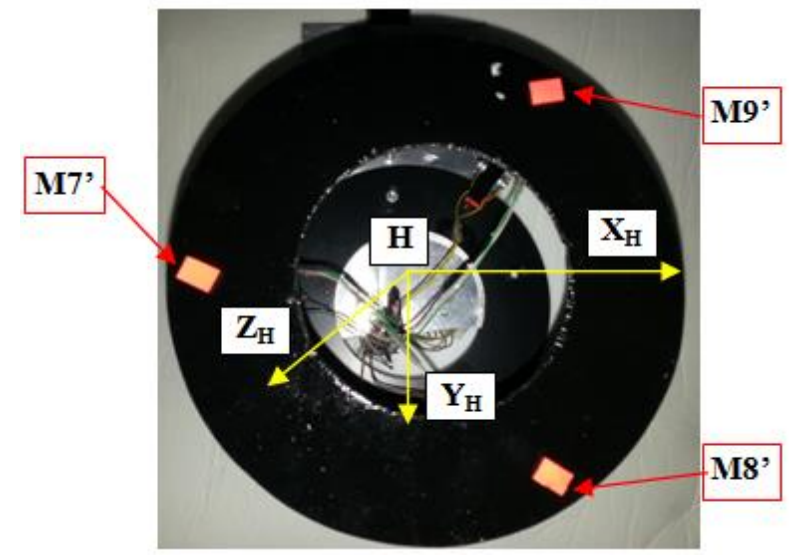

b)

Fig. 10. Location of markers for BAPAMAN 1 tests: (a) lateral view, (b) bottom view.

The accuracy of CONTEMPLAS system can be affected by several aspects such as lighting conditions, number of used cameras, location of cameras, cameras frame rate, accuracy of the calibration process. During the specific experimental tests within this paper, the equipment accuracy can be estimated as about $0.5 \mathrm{~mm}$ when using two cameras at an acquisition rate of 250 frames/second.

\section{Experimental results with CONTEMPLAS}

BAPAMAN1 is capable to achieve eight binary configurations. All the combinations of the eight binary configurations have been tested to obtain the trajectories for BAPAMAN1 workspace evaluation. For example, Fig. 11 shows a photo sequence of BAPAMAN1 during a motion from the initial configuration with all the actuators turned off (000) to the final configuration with only leg 3 actuated (001).

During each test it has been possible to obtain plots of the displacements of the points of interest M7, M8 and M9 as reported for example in Fig.12 for test no.4 from starting configuration (000) to final configuration (101). Similarly, it has been possible to plot the angular displacements during a movement of BAPAMAN1. For example, Fig.13 shows the results of experimental tests in terms of joint angle motion range of each leg (a1, a2 and a3) during a motion from binary combination (000). In particular, Fig.13a) shows the evolution of $\alpha 1$ when moving from the binary combination (000) to (010). Similarly, Fig.13b) shows the evolution of $\alpha 1$ and $\alpha 2$ when moving from the binary combination (000) to the binary combination (110). Fig.13c) shows the evolution of $\alpha 1, \alpha 2$ and $\alpha 3$ when moving from the binary combination (000) to the binary combination (111).

Each experimental test has been repeated several times to get a statistical evaluation of maximum values as summarized in Table 3. For all binary configurations the BAPAMAN1 behaviour is very smooth without any discontinuities during flexural joints actuation. The maximum displacement value of the first leg on Z-axis is $13 \mathrm{~mm}$. In case of first binary configuration (100) it can be seen on the angular amplitude of $\alpha 1$ a slightly lower value as compared to other binary configurations. Also it can be observed that the angular amplitude reaches highest values when two flexural joints are actuated simultaneously. The above-mentioned numerical results have been summarized in Table 3. They show a suitable operation of BAPAMAN1 also in terms of angular ranges of flexural joints that, in some cases, are even larger than the design value of $35 \mathrm{deg}$ that was defined at design stage. as required at design stage.

Based on the obtained experimental data it has been possible to calculate the position workspace of BAPAMAN1 as referring to the centre of its movable plate as detailed in Table 3. Also it has been possible to calculate the path that has been described by the centre of the movable plate during each test. In particular, in Fig. 15 it is presented the trajectory of point $\mathrm{M}$ for binary combination 100 . The maximum value of the first leg on $\mathrm{Z}$-axis is $4.7 \mathrm{~mm}$. Similar computations have been made for all other feasible trajectories of BAPAMAN1 operation as summarized in Table 4.

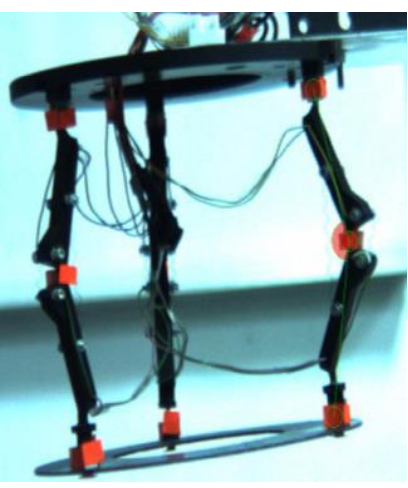

a)

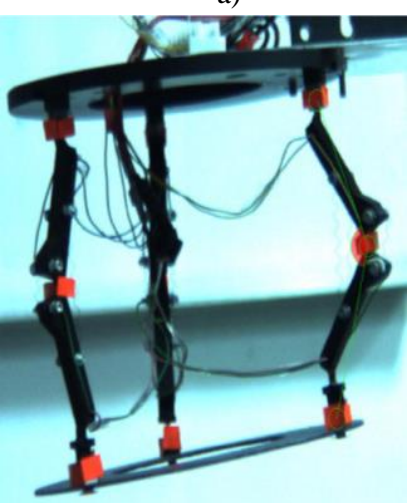

c)

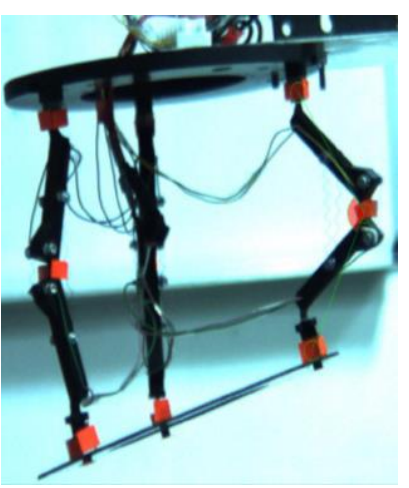

b)

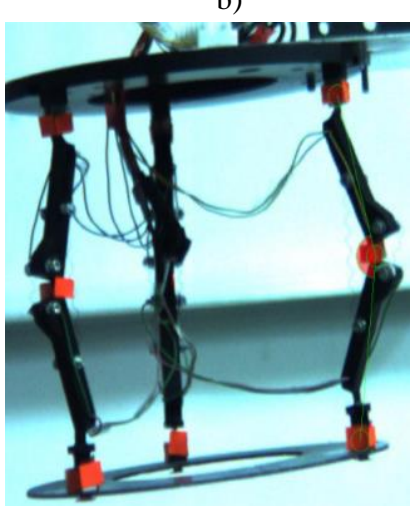

d)
Fig. 11. A photo sequence of BAPAMAN1 during the experimental tests for binary combination no. 3 in Table 1. 
Table 3 - Experimental results during BAPAMAN1 tests

\begin{tabular}{||c||c|c|c|c|c|c|c|c||}
\hline \multirow{4}{*}{$\begin{array}{c}\text { Test operation } \\
\text { conditions }\end{array}$} & Test session & 1 & 2 & 3 & 4 & 5 & 6 & 7 \\
\cline { 2 - 11 } & Start configuration & 000 & 000 & 000 & 000 & 000 & 000 & 000 \\
\cline { 2 - 11 } & Final configuration & 100 & 010 & 001 & 011 & 101 & 110 & 111 \\
\hline $\begin{array}{c}\text { Maximum } \\
\text { displacement of } \\
\text { reference points [mm] }\end{array}$ & $\mathrm{M}_{1}$ & 13.0 & 4.3 & 5.5 & 7.1 & 6.3 & 5.0 & 15.8 \\
\cline { 2 - 11 } & $\mathrm{M}_{2}$ & 1.6 & 35.0 & 8.0 & 43.1 & 21.8 & 39.1 & 59.5 \\
\hline $\begin{array}{c}\text { Maximum angular } \\
\text { displacement of flexural } \\
\text { joints [deg] }\end{array}$ & $\mathrm{M}_{3}$ & 1.1 & 6.0 & 52.4 & 61.1 & 53.4 & 39.1 & 38.5 \\
\cline { 2 - 11 } & $\alpha_{1}$ & 19.9 & 0.0 & 0.0 & 0.0 & 41.6 & 22.7 & 29.4 \\
\hline \hline
\end{tabular}

Table 4 - Computed maximum workspace

\begin{tabular}{|c|c|c|c|c|c|c|c|}
\hline Test no. & 1 & 2 & 3 & 4 & 5 & 6 & 7 \\
\hline $\begin{array}{l}\text { Final } \\
\text { config. }\end{array}$ & 100 & 010 & 001 & 011 & 101 & 110 & 111 \\
\hline $\mathrm{X}_{\mathrm{H}}[\mathrm{mm}]$ & 1.2 & 3.9 & 2.0 & 3.1 & 1.0 & 0.1 & 1.9 \\
\hline $\mathrm{Y}_{\mathrm{H}}[\mathrm{mm}]$ & 2.4 & 2.5 & 4.6 & 6.1 & 0.5 & 3.8 & 5.7 \\
\hline $\mathrm{Z}_{\mathrm{H}}[\mathrm{mm}]$ & 4.7 & 14.3 & 23.1 & 40.1 & 29.1 & 22.0 & 43.2 \\
\hline
\end{tabular}

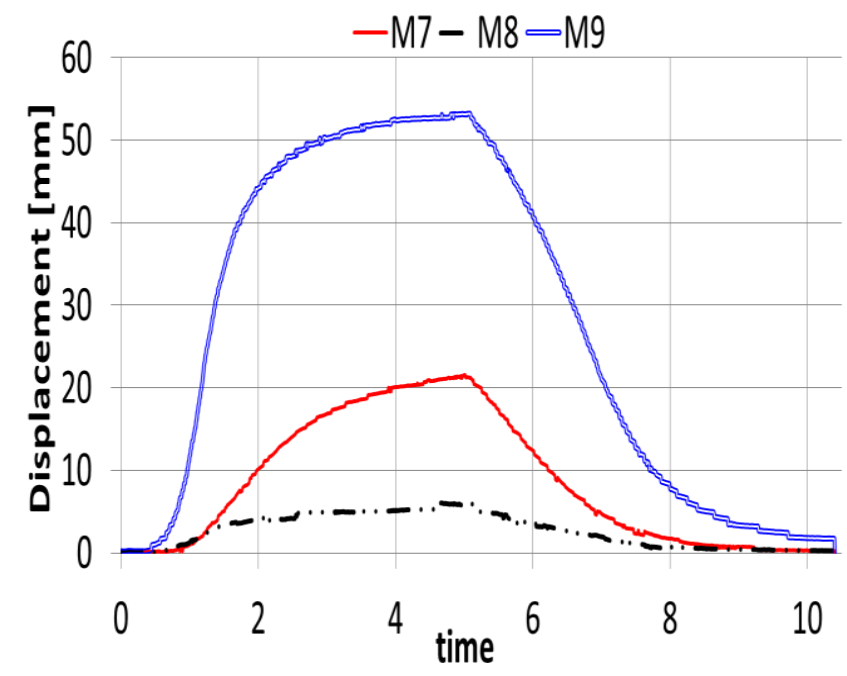

Fig. 12. Experimentally measured displacement module of points M7, M8, M9 during test no.4 from configuration (000) to configuration (101).

Given the proposed architecture, design materials and manufacturing, the built BAPAMAN 1 shows a satisfactory workspace, in particular, with a relatively large motion range of the actuated joints. However, the results obtained with CONTEMPLAS set-up show values significantly differing from those that have been obtained with Milli-CaTraSys set-up such as reported in Figs.7 and 8. This demonstrates strong effects of the external loads to the operation of BAPAMAN 1 in terms of large compliant displacements. Accordingly, further investigations will be carried out in a near future for achieving design improvements, in particular, in terms of higher stiffness as well as higher payload and accuracy performance.

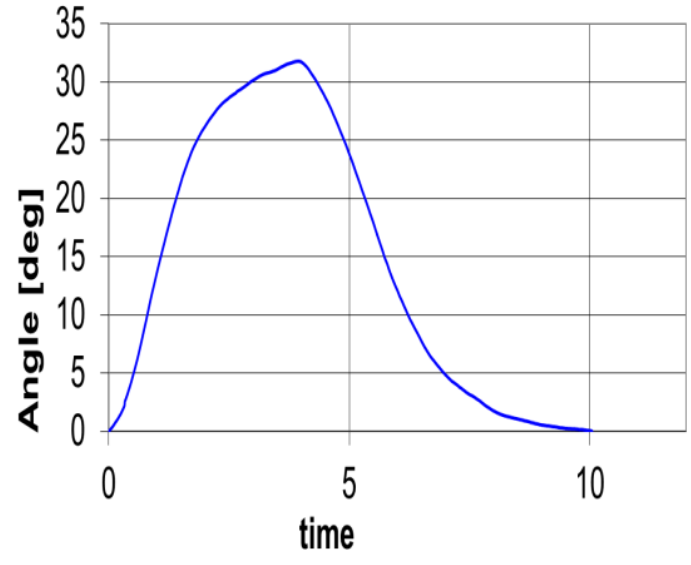

a)

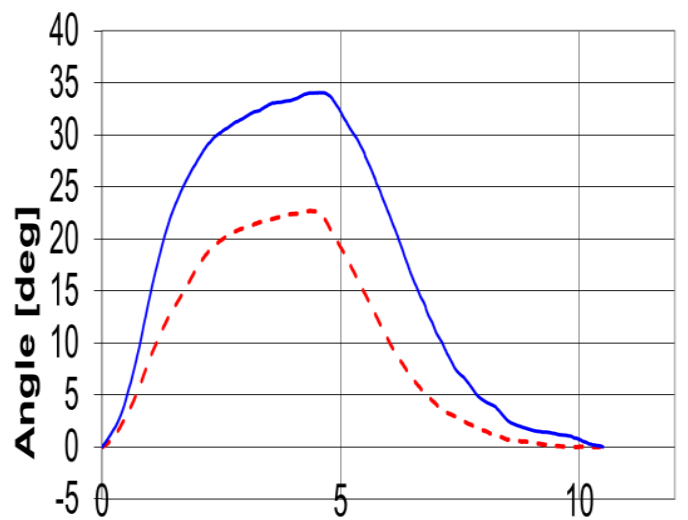

b)

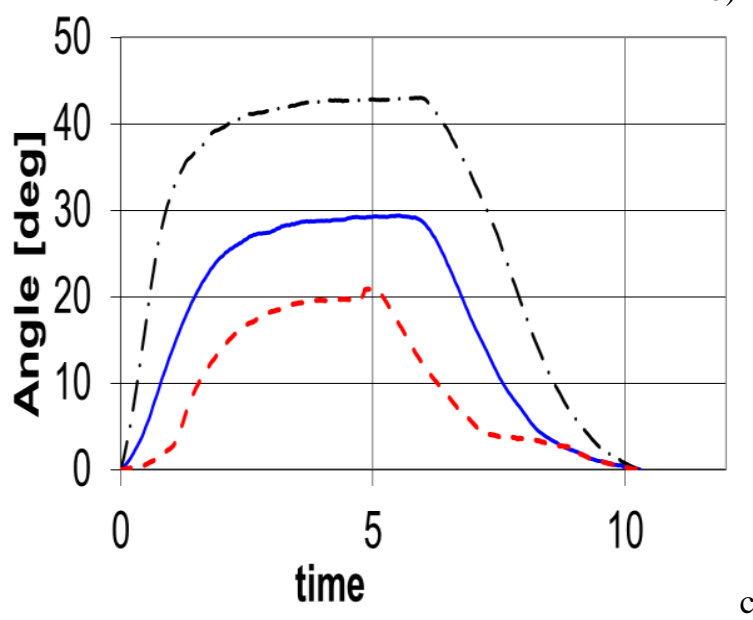

Fig. 13. Results of experimental tests during a motion from binary combination (000): a) to the binary combination (010) with only leg 2 moving; b) to the binary combination (110) with legs 1 and 2 moving; c) to the binary combination (111) with all legs moving. 


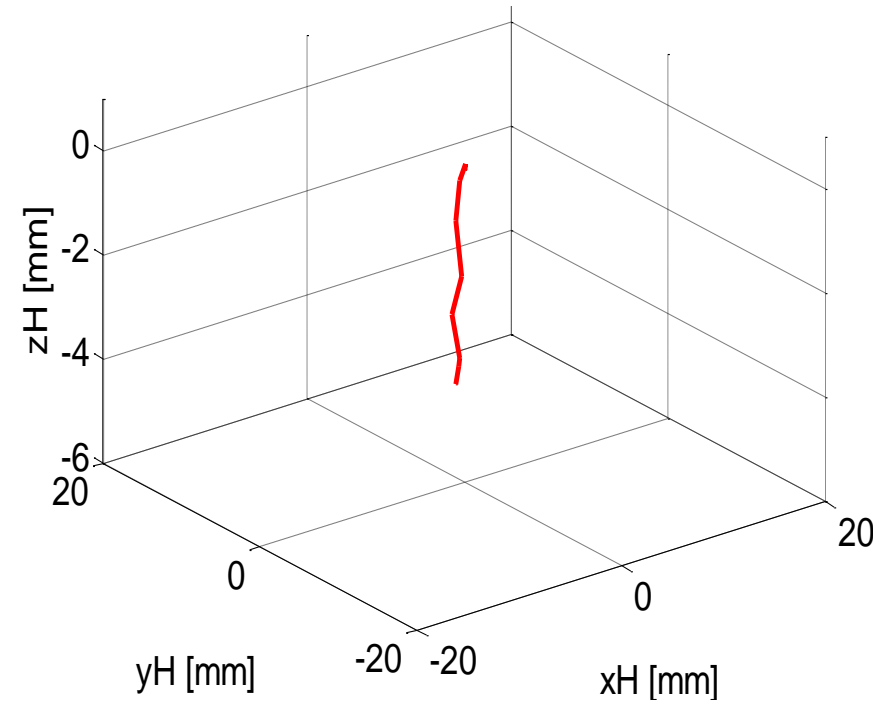

Fig. 14. Plot of the path described by the centre of the movable plate of BAPAMAN1 during the experimental test no.1.

\section{Conclusions}

This paper has described the main design issues and characteristics of BAPAMAN manipulators. This manipulator has interesting low-cost and easy-operation design features that have been achieved by using flexural joints and shape memory alloy actuators. Given the peculiarities of BAPAMAN architecture, a detailed experimental characterization has been reported with tests on a built 3-DOF binary spatial parallel manipulator whose name is BAPAMAN1. Specific experimental set-ups have been settled up: one has been conceived by referring to the Milli-CaTraSys measuring system and one has been conceived as based on a CONTEMPLAS high-speed motion analysis equipment. Several experimental tests have been carried out with the aims to validate the proposed mechanical design and to evaluate the practical workspace operation performances and characteristics of the built prototype. Experimental results show that the tested prototype can perform eight binary configurations and has a suitable reachable workspace as compared with the prescribed design characteristics. In particular, a relatively wide orientation angle of 25 degrees as been achieved with BAPAMAN 1 in continuous operation. Further investigations shall be carried out in a future for further reducing the manipulator size as well as further increasing its performances especially in terms of higher stiffness, payload, accuracy performances.

\section{Acknowledgement}

The author wishes to acknowledge the collaboration of Prof. Annika Raatz and her team at Technical University of Braunschweig for the development of the prototypes of BAPAMAN 1 and 2. The author is also indebted with Dr. Christian Petre Copilusi and Dr. Tao Li for their collaboration to the experimental tests during their stay at LARM.

\section{References}

[1] CECCARELLI, M., "Fundamental of Mechanics of Robotic Manipulator", Springer, Dordrecht, 2004.

[2] MERLET J.P., "Parallel Manipulators", Springer, Dordrecht, 2006.

[3] HESSELBACH J., RAATZ A., "Pseudo-elastic flexure-hinges in robots for micro assembly", Proceedings of SPIE Microrobotics and Microassembly II, Boston, pp. 157-167, 2000
[4] AVEDILLO J.G., CHOI D.Y., RIVIERE C.N., "Inverse kinematic model of flexure-based microsurgical manipulator", Proceedings 27th IEEE Engineering in Medicine and Biology, Shanghai, pp. 5775-5777, 2004.

[5] SUJAN V. A., DUBOWSKY S., "Design of a lightweight hyper-redundant deployable binary manipulator", Journal of Mechanical Design, Vol. 126, pp. 29-39, 2004.

[6] KANG B.H., WEN J.T., DAGALAKIS N.G., GORMAN J.J., “Analysis and design of parallel mechanisms with flexure joints", IEEE Transactions on Robotics, Vol.21, N.6, pp. 1179-1185, 2005.

[7] SUTHAKORN J., "Binary hyper-redundant robotic manipulator concept", Proceedings of IEEE Region 10 International Conference TENCON 2004, Vol. 4, pp. 625-628, 2004.

[8] LEE D.S., CHIRIKJIAN G.S., "A combinatorial approach to trajectory planning for binary manipulators", Proceedings of the IEEE International Conference on Robotics and Automation ICRA'96, Minneapolis, pp. 2749-2754, 1996.

[9] LICHTER, M.D., SUJAN, V.A., DUBOWSKY, S., "Computational issues in the planning and kinematics of binary robots", Proceedings of the IEEE International Conference on Robotics and Automation ICRA 2002, Washington DC, pp.341-346, 2002.

[10] LOBONTIU N., "Compliant mechanisms: design of flexure hinges", CRC press, Boca Raton, 2003.

[11] YI B., NA H., CHUNG G.B., KIM W.K., SUH I.H., "Design and experiment of a 3DOF parallel micro-mechanism utilizing flexure hinges", IEEE Transactions on Robotics and Automation, vol. 19 (4), pp. 604-612, 2003.

[12] LAGOUDAS D.C., "Shape Memory Alloys: modeling and engineering applications", Springer-Verlag, Dordrecht, 2008.

[13] DUNLOP R., GARCIA A., "A Nitinol Wire Actuated Stewart Platform", Proceedings of Australian Conference on Robotics and Automation. Auckland, pp. 122-127. 2002.

[14] MALIK A., AMIRTHAM V., NAGARAJAN T., "SMA Actuator Tehnology Application in Stewart Platform Construction", Journal of Applied Sciences, Vol.11, N.23, pp.3783-3790, 2011.

[15] RAPARELLI T., ZABEL P.B., DURANTE F., "Design of a Parallel Robot Actuated by Shape Memory Alloy Wires", Materials Transaction 43(5), pp.1015-1022, 2002.

[16] OTTAVIANO E., CARBONE G., CECCARELLI M., "Workspace analysis and performance of a binary actuated parallel manipulator with flexure hinges", Proceedings of the Institution of Mechanical Engineers, Part C: Journal of Mechanical Engineering Science, Vol. 217 (3), pp. 313-330, 2003.

[17] CARBONE G., LIANG C., GU H., CECCARELLI M., BURISCH A., RAATZ A., "Design and Simulation of a Binary Actuated Parallel Micro-Manipulator", 13th IFToMM World Congress in Mechanism and Machine Science, CD Proceedings, Guanajuato, 2011.

[18] BORCHERT G., LÖCHTE C., CARBONE G., RAATZ A., "A modular design kit for task-adaptable low-cost robots based on BaPaMan design", International Journal Frontiers of Mechanical Engineering, Vol.8, n.1, pp 33-41, 2013.

[19] CARBONE G., D'ALIESIO E., BORCHERT, G., RAATZ, A., "Design and validation of the binary actuated parallel manipulator BAPAMAN2", International Journal Advanced Robotics, Vol. 27, n.13, pp.1033-1043, 2013.

[20] HERNÁNDEZ-MARTÍNEZ E.E., CECCARELLI M., CARBONE G., LÓPEZ-CAJÚN C.S., JÁUREGUI-CORREA J.C., "A Characterization of Milli-CaTraSys System with a Parallel Manipulator Architecture", International Journal Mechanics Based Design of Structures and Machines, Vol.38, n.1, pp.25-49, 2010.

[21] HERNANDEZ-MARTINEZ E.E., CARBONE G., LOPEZ-CAJUN C., "Operation Features of Milli-CaTraSys", Proceedings of the 2nd European Conference on Mechanism Science EUCOMES'08, Springer, Dordrecht, pp. 191-199, 2008.

[22]CONTEMPLAS Webpage, "Products, Hardware, Cameras", http://www.contemplas. com/, last visited on July 2015.

[23]CARBONE G., CECCARELLI M., "A Procedure for Experimental Evaluation of Cartesian Stiffness Matrix of Multibody Robotic Systems", 15th CISM-IFToMM Symposium on Robot Design, Dynamics and Control, Romansy, 2006, Montreal, Paper Rom04-24.

\section{Biographical notes}

CARBONE Giuseppe has received his $\mathrm{PhD}$ from University of Cassino and South Latium. He has carried out several periods of research abroad such as in Germany, Japan, Spain, and China. His research interests include stiffness of multibody robotic systems, robotic hands and grippers, mechatronic designs, design of experimental test-beds. He has published more than 250 peer reviewed papers on the above-mentioned topics. 